\title{
Les transformations de l'industrie et ses conséquences spatiales en Pologne (1989-2016)
}

Industrial change and its spatial consequences in Poland (1989-2016)

Der Wandel der Industrie und seine räumlichen Folgen in Polen (1989-2016)

\section{Anna Geppert et Iwona Pielesiak}

\section{(2) OpenEdition}

Journals

Édition électronique

URL : http://journals.openedition.org/rge/6260

ISSN : 2108-6478

Éditeur

Association des géographes de l'Est

Référence électronique

Anna Geppert et Iwona Pielesiak, «Les transformations de l'industrie et ses conséquences spatiales en Pologne (1989-2016) », Revue Géographique de l'Est [En ligne], vol.57 / 1-2 | 2017, mis en ligne le 23 octobre 2017, consulté le 08 septembre 2020. URL : http://journals.openedition.org/rge/6260

Ce document a été généré automatiquement le 8 septembre 2020

Tous droits réservés 


\section{Les transformations de l'industrie et ses conséquences spatiales en Pologne (1989-2016)}

Industrial change and its spatial consequences in Poland (1989-2016)

Der Wandel der Industrie und seine räumlichen Folgen in Polen (1989-2016)

Anna Geppert et Iwona Pielesiak

1 A la mémoire du Professeur Stanisław Liszewski (1940-2016), géographe et urbaniste.

\section{Introduction}

2 En Europe occidentale, les trente dernières années ont vu une nouvelle phase de désindustrialisation liée à la délocalisation des activités productives vers des pays où les coûts de production, et notamment de main d'œuvre, sont faibles. En Europe centrale et orientale, les évolutions complexes associent désindustrialisation et réindustrialisation. D'un côté, la dislocation du Conseil d'aide économique mutuelle (CAEM) a fait disparaître les débouchés garantis par la division internationale du travail au sein du bloc socialiste, mettant à jour la vétusté du système productif. Ceci entraîna, dans les secteurs traditionnels de l'industrie, des crises violentes au coût social élevé. A l'inverse, l'entrée dans l'Union européenne et donc dans le marché commun, la présence d'une main d'œuvre qualifiée à faible coût, la proximité géographique et culturelle ont attiré les investissements directs étrangers (IDE). Parallèlement, un nouvel entrepreneuriat national et local émerge. La Pologne, de loin le plus grand des anciens satellites de l'URSS, fait figure de bon élève. Depuis 1992, le pays n'a jamais connu de taux de croissance négatif, y compris lorsque l'Europe était traversée par la crise de 2008: on parle de "miracle polonais". Aujourd'hui, la Pologne est un pays largement industriel où le secteur secondaire représente 30,2\% de l'emploi et 31,6 \% du $\mathrm{PIB}^{1}$. Au cours des vingt dernières années (1995-2015), son évolution diffère de la plupart des pays de l'Union européenne. L'emploi industriel a baissé $(-9,1 \%)$, mais à un 
rythme trois fois moins rapide que la moyenne communautaire. ${ }^{2}$ Surtout, à contrecourant de la tendance européenne, la part de la valeur ajoutée brute industrielle a augmenté $(+8,2 \%)^{3}$.

Aussi, plutôt que de désindustrialisation, il convient de parler de transformations de l'industrie. En effet, le gain de productivité observé est le fruit d'une série de mutations profondes. L'effondrement de l'industrie manufacturière n'a que rarement donné naissance à des modernisations réussies. Par contre, le développement de secteurs d'activités nouveaux, la recomposition des filières, sont bien réels. Dans l'espace polonais, ces mutations produisent des effets différenciés qui accentuent les inégalités territoriales opposant l'ouest à l'est du pays, les métropoles aux villes petites et moyennes, les centres aux périphéries des villes. De nombreuses politiques de restructuration et de soutien aux activités industrielles ont été mises en œuvre. Le recul de près de trente ans depuis la chute du mur de Berlin permet d'interroger leur sens : s'agit-il de remèdes palliatifs, ou peuvent-elles réellement changer la donne?

4 Le présent article s'appuie sur la richesse des travaux de l'école polonaise de géographie, dont le regretté Professeur Liszewski fut l'un des fondateurs. Les données statistiques proviennent de l'office statistique de l'Union européenne Eurostat et de l'institut statistique polonais GUS ${ }^{4}$. La synthèse proposée entreprend d'éclairer les transformations spatiales induites par la recomposition de la géographie industrielle polonaise et d'interroger les effets des politiques publiques menées depuis trente ans.

5 La première partie présente la structuration industrielle du territoire polonais dans le temps long, qui fonde ses équilibres actuels. La deuxième partie s'appuie sur une analyse sectorielle pour analyser les transformations des activités productives depuis la crise, brutale mais brève, des années 1989-1992. La troisième partie revient au territoire pour évaluer les effets des mutations de l'industrie et des politiques d'aménagement sur l'espace.

\section{De fortes différenciations régionales façonnées par I'histoire nationale}

6 Dans la Pologne contemporaine, le dynamisme des régions occidentales contraste avec l'atonie de la "façade orientale" en proie aux difficultés économiques et démographiques. Ces disparités régionales trouvent leur origine dans les processus d'industrialisation du pays aux dix-neuvième et vingtième siècles, eux-mêmes liés aux vicissitudes de l'histoire polonaise.

\section{A. Trois puissances occupantes aux politiques industrielles différentes}

$7 \mathrm{Au}$ XIXe siècle, l'industrialisation s'inscrit dans les contextes très différents des trois puissances occupantes qui se partagent la Pologne à la fin du XVIIIe siècle : la Russie, elle-même en retard d'industrialisation, l'Autriche, peu impliquée sur le territoire et la Prusse, où l'industrialisation bat son plein (Fig. 1).

8 Pour l'Empire russe, la Pologne représente un glacis géostratégique. L'occupant n'investit pas dans les infrastructures, ni dans l'appareil productif. Varsovie, principale ville du secteur russe, est enserrée dans un réseau de citadelles et son extension 
interdite. Les industries s'implantent dans les petites villes voisines comme Praga (en rive droite de la Vistule, aujourd'hui intégrée à Varsovie). A Marymont (banlieue sud de Varsovie), les frères Łubieński ne peuvent développer leur filature de lin. En 1833, ils la déplacent dans leur domaine situé à une trentaine de kilomètres à l'ouest, où elle donnera naissance au développement de la ville de Żyrardów ${ }^{5}$. L'unique investissement industriel lourd se situe à proximité de la Silésie, à DĄbrowa, où l'éphémère royaume du Congrès implante l'aciérie Huta Bankowa qui restera longtemps la plus importante de l'empire Russe. Dans le reste du secteur russe, les centres industriels qui se développent sont le fruit d'initiatives individuelles, le plus souvent dans le textile qui ne nécessite pas d'investissement lourd. tódź, qui connaît le plus fort taux de croissance démographique des villes européennes du XIXe siècle, en offre un bel exemple. Une multitude de tisserands s'implante le long de la voie principale (actuelle rue Piotrkowska). Leur disposition est caractéristique de la proto-industrie : habitation en front de rue, des ateliers qui s'étirent jusqu'au fond de longues parcelles. L'apparition de grandes fabriques entourées d'habitat ouvrier n'intervient qu'à partir des années 1870, lorsque plusieurs générations d'entrepreneurs (Poznański, Scheibler, Heinzel) ont accumulé le capital nécessaire.

9 L'Autriche, attirée par les mines de sel des environs de Cracovie, occupe la Galicie. L'instauration de la double monarchie austro-hongroise (1867) confère à la région, par ailleurs très excentrée, une relative autonomie. La découverte de gisements pétroliers dans les années 1850 ouvre une brève ruée vers l'or justifiant la construction d'une liaison ferroviaire suivant le nord des Carpates. Les villes galiciennes, Cracovie et Lwów ${ }^{6}$, connaissent une industrialisation mesurée, orientée vers les débouchés locaux. Leur urbanisation est davantage liée à leurs fonctions administratives, tertiaires et universitaires. L'université Jagellone est autorisée à enseigner en polonais, à la différence des établissements situés dans les territoires sous occupation russe ou prussienne. Les élites polonaises s'y regroupent et Cracovie retrouve son statut de centre intellectuel et culturel, ce qui lui permettra un développement rapide lors de l'indépendance de la Pologne.

10 A l'ouest, la Prusse est en pleine expansion industrielle. Le développement industriel et minier de la Silésie donne naissance à une constellation de villes qui deviendra la conurbation de Katowice/Kattowitz. La capitale silésienne, Wrocław/Breslau, connaît un essor qui en fait, à la veille de la seconde guerre mondiale, la sixième ville de l'empire allemand. Plus au nord, les grandes villes accueillent des industries textiles et mécaniques (Poznań), développent leurs activités portuaires (Szczecin/Stettin, Gdańsk/ Dantzig). Elles bénéficient, au long du XIXe siècle, d'importants investissements dans l'appareil productif, les infrastructures de transport, ou encore l'enseignement supérieur technique. 
Fig. 1. L'industrie dans l'espace polonais (élaboré par A. Geppert et I. Pielesiak, 2017)

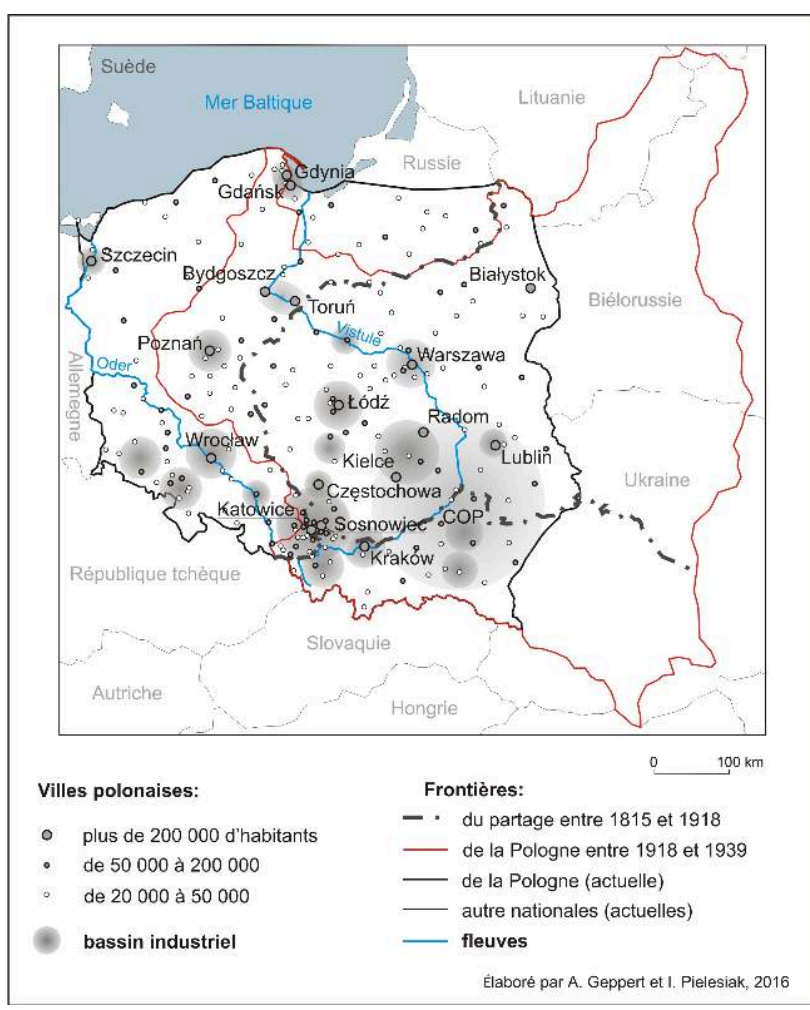

\section{B. L'aménagement industriel d'une nation renaissante}

11 La Pologne retrouve sa souveraineté à la fin de la première guerre mondiale. La Deuxième République (1918-1939) entreprend un effort de construction aux fruits impressionnants, compte tenu de sa courte durée. L'industrialisation doit garantir la base économique de l'indépendance. Une véritable politique industrielle d'aménagement du territoire est mise en place. En 1927, 22 bassins industriels ${ }^{7}$ sont définis (Gierańczyk et Stańczyk, 2001). Dans le nord du pays, ils se situent dans les principaux centres urbains. Dans le sud, le bassin industriel de Haute Silésie ${ }^{8}$ (GOP) prévoit le développement d'industries de précision pour l'automobile, l'aviation, l'armement. Plus à l'est, le Bassin Industriel Central ${ }^{9}$ (COP) est créé à égale distance des frontières russe et prussienne.

Intégrer les trois composantes du territoire national passe par l'amélioration des infrastructures de communication, de qualité inégale et mal interconnectées. Les limites territoriales de la Deuxième République n'offrent à la Pologne d'accès à la mer que par l'étroit corridor de Dantzig. Le débouché maritime est assuré par la construction du port de Gdynia. Construite ex nihilo, c'est une ville nouvelle conçue dans l'esprit du modernisme. De 1926 à 1933, une liaison ferroviaire nord-sud est construite pour réunir la Silésie au port de Gdynia. 


\section{L'industrie lourde, fer de lance idéologique de la République Populaire de Pologne}

13 A l'issue de la seconde guerre mondiale, la République Populaire de Pologne a perdu ses régions orientales, rattachées à l'URSS. En compensation, la frontière occidentale intègre des territoires prélevés sur l'Allemagne. Pour la réalisation du projet socialiste, l'industrie est une base économique nécessaire et un fer de lance idéologique. Cependant, les ressources sont modestes. La politique industrielle s'appuie sur les centres industriels existants, ne modifiant que marginalement les grands équilibres du territoire national. Les grandes entreprises sont nationalisées. Les investissements nouveaux sont dédiés aux industries lourdes : chantiers navals de Gdańsk, aciéries de CZĘstochowa, extraction du soufre dans le bassin de Tarnobrzeg, industries chimiques à Puławy. Inversement, les industries des biens de consommation sont sous-representées (Domański, 2006).

Dans les villes, il faut casser les structures spatiales bourgeoises. Cracovie, foyer du conservatisme, est flanquée d'un gigantesque combinat métallurgique (Fonderie Lénine) et de sa ville-modèle, Nowa Huta (Nouvelle Fonderie). Exceptionnel par son ampleur, ce laboratoire du socialisme est conçu pour 100000 habitants. Le centre-ville, doté d'un plan majestueux dû à Tadeusz Ptaszycki et d'une architecture sociale-réaliste, est aujourd'hui classé. Nowa Huta est dotée d'équipements culturels de rang national, mais les habitants devront lutter vingt ans pour obtenir la construction d'une église. Plus généralement, l'idéologie socialiste conduit à maintenir l'industrie au cœur des villes, à la différence de l'Europe occidentale où des zones industrielles suburbaines sont aménagées à partir des années 1950.

L'industrie communiste est fortement consommatrice en main d'œuvre, souvent de faible valeur ajoutée (industries lourdes, textiles...). L'appareil productif n'est guère modernisé (Gierańczyk et Stańczyk, 2001). Certaines usines fonctionnent avec des machines d'avant-guerre, voire du XIXè siècle. En 1974, Andrzej Wajda, met en scène la condition ouvrière à Łódź dans les années 1880 dans son film Terre promise ${ }^{10}$. Le tournage a lieu dans les usines Scheibler (alors Uniontex), et Poznański (alors Poltex), sans qu'il soit besoin de modifier leurs intérieurs. Les deux usines fonctionneront, inchangées, jusqu'à la chute du régime. En conséquence, les industries et friches industrielles demeurent, encore aujourd'hui, très présentes dans le centre-ville : une caractéristique que l'on retrouve, à un degré un peu moins marqué, dans la plupart des villes polonaises. 
Fig. 2. Les industries dans le territoire de la ville de Łódź (élaboré par A. Geppert et I. Pielesiak, 2017)

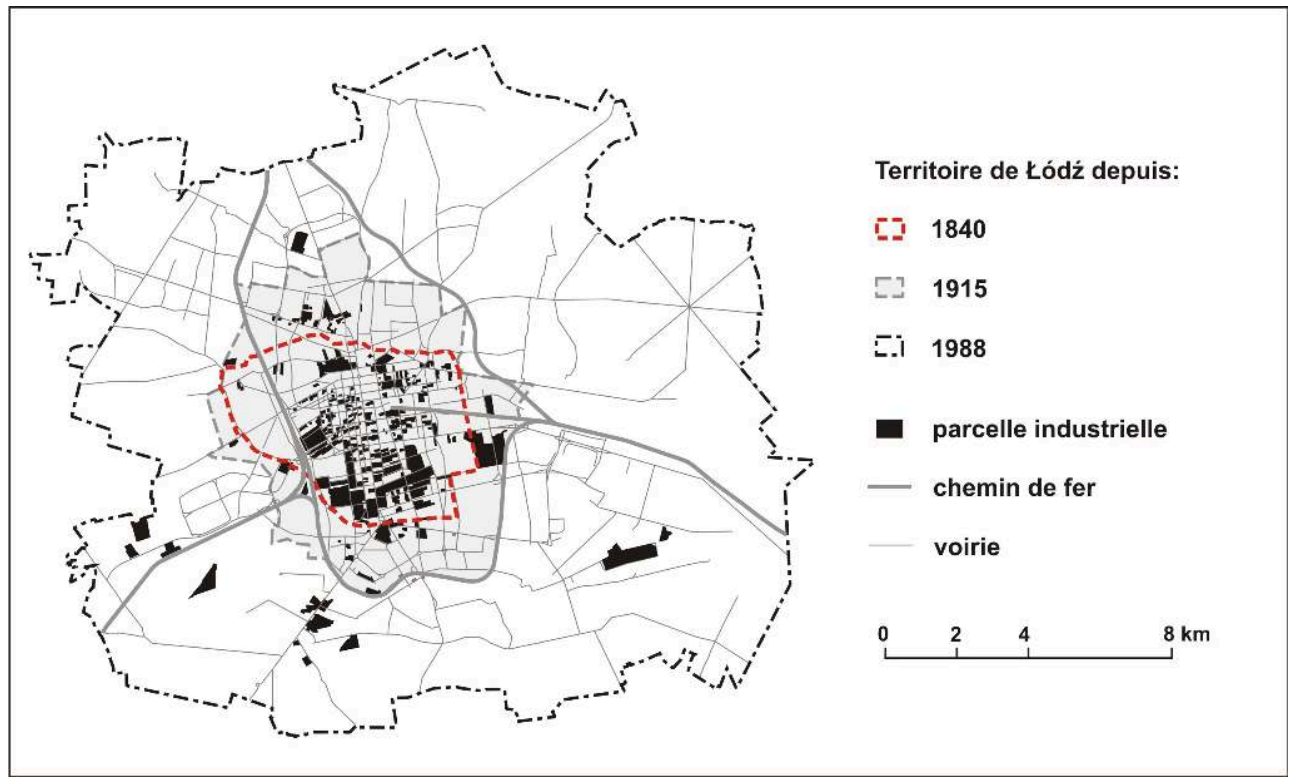

\section{Une adaptation à l'économie de marché différenciée selon les secteurs d'activité}

L'entrée dans l'économie de marché entrâne une crise brutale qui révèle la vétusté de l'appareil productif. Une modernisation au forceps échoue dans les industries de première transformation, mais amène un développement réel des industries des biens de consommation.

\section{A. Les leçons d'une crise brutale mais brève}

La sortie de l'économie planifiée entraîne une crise sévère. D'une part, le marché d'exportation vers les pays socialistes disparaît avec le CAEM. D'autre part, la demande intérieure est faible. Confiante dans la main invisible du marché, la Troisième République de Pologne compte sur un redressement rapide et spontané. En mai 1990, le niveau de la production nationale chute de $50 \%$ par rapport à l'année précédente (Kaliński, 2009). Le gouvernement applique une thérapie de choc, le «plan de Balcerowicz $»^{11}$, pour adapter l'économie polonaise. Les entreprises nationales sont privatisées, dans l'espoir d'attirer les capitaux nécessaires pour moderniser l'appareil productif. Pour pallier l'absence d'accumulation de capital pendant la période socialiste et la faiblesse du système bancaire, on compte sur l'apport des IDE. Mais les investisseurs privilégient, logiquement, les établissements les plus rentables, laissant de côté ceux en difficulté (Rachwał, 2006).

En 1993, un embryon de politique industrielle est mis en place pour soutenir les secteurs les plus en difficulté. Les recettes des privatisations doivent abonder un Fonds de restructuration de l'industrie. Cependant, les prix de cession sont calculés d'après la production des établissements concernés, alors au plus bas, et les recettes sont largement insuffisantes. Ces prix sont également très inférieurs à la valeur économique 
d'un patrimoine qui, moyennant une reprise de la production, retrouve sa valeur. Pour certains auteurs, l'appareil productif national fut tout simplement bradé (Miedziński, 2015). Les privatisations entraînent des réorganisations. Les trains de licenciements conduisent à une augmentation violente du chômage et l'emploi industriel diminue de 40\% entre 1989 et 2001 (Bartosik, 2013). Dans les plus grandes entreprises, on observe les externalisations caractéristiques de l'entrée dans le post-fordisme (Wiedermann, 2004). Les actifs non productifs, comme les centres de vacances pour les salariés, sont revendus.

De coût social élevé, la crise est brève. La production industrielle cesse de baisser en 1992. La reprise est rapide, notamment parce que les Polonais font preuve d'un fort “esprit d'entreprise" (Domański, 2006). A partir de 2004, l'entrée de la Pologne dans l'Union européenne entraîne une augmentation rapide des investissements directs étrangers (IDE), accompagnée d'une augmentation de la production, tant en quantité qu'en valeur ajoutée (Ciechowski, 2014). Cependant, il y a des gagnants et des perdants : le textile, sinistré, a quasiment disparu, les industries lourdes peinent à se réformer tandis que d'autres secteurs d'activité parviennent à s'adapter et mettent sur le marché de nouveaux produits. La période qui commence verra une évolution du poids relatif des secteurs d'activité (Fig. 3).

Fig. 3. Evolution de la structure de la production industrielle 1990-2015

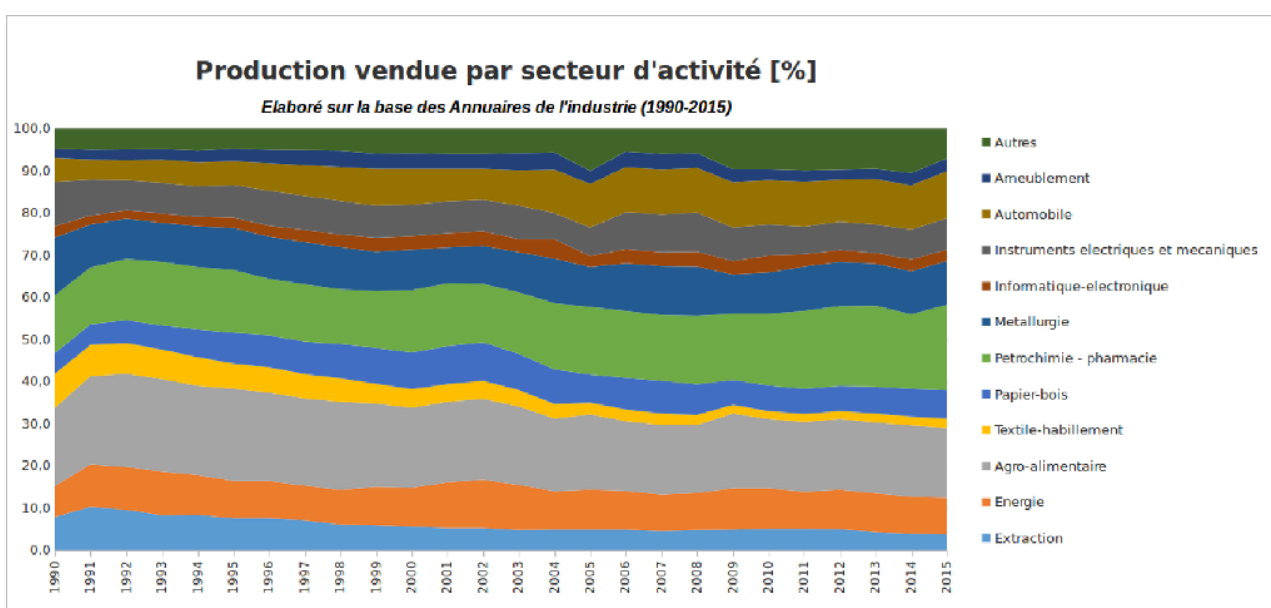

\section{B. L'impossible restructuration des industries de première transformation}

Les industries traditionnelles (textile, métallurgie, extraction) s'étaient maintenues jusqu'à la chute du régime de manière quelque peu artificielle. La garantie du plein emploi permettait de maintenir des effectifs salariés pléthoriques aux rémunérations faibles, compensant le sous-investissement dans l'appareil productif. La division socialiste du travail assurait des débouchés à une production de qualité inégale. La violence $d u$ choc du passage à l'économie de marché entraîne une modernisation radicale qui, au-delà des particularités sectorielles, présente des traits communs. Les restructurations internes réduisent le nombre d'unités organisationnelles des entreprises. Qu'il s'agisse de production ou d'administration (management, comptabilité, gestion...), services et départements sont supprimés ou fusionnés. Les 
fonctions support (transport, sécurité, nettoyage industriel) sont externalisées. Les fonctions de commandement sont décentralisées, déléguant plus de compétences aux niveaux inférieurs. Des fonctions nouvelles se développent, contrôle qualité, marketing, informatique. La production se spécialise, laissant de côté les segments et produits moins rentables, et la standardisation des produits permet des gains de productivité (Lachiewicz et Zakrzewska-Bielawska, 2010).

21 Le secteur minier s'enlise dans une reconversion qui n'en finit pas. Enfants chéris, parfois bras armés du régime, les mineurs bénéficiaient de nombreux avantages sociaux. Dans les années 1990, le charbon et la houille, sources d'énergie toujours très utilisées en Pologne, affrontent la baisse des prix mondiaux. En 1990, les mines sont transformées en sociétés anonymes à fonds publics et se lancent dans une concurrence impitoyable. Le manque de rentabilité entraîne des fermetures de mines, socialement difficiles et politiquement sensibles. Les sociétés qui survivent accumulent les dettes. Dans les années 1993-1995, le système est à nouveau refondu. Afin de mutualiser la dette, six sociétés nationales adossent des mines en faillite à des mines rentables. Dans les années 1998-2002, une série de plans sociaux misant sur les départs volontaires produit peu d'effet. En 2003-2006, un second mouvement de concentration réunit cinq coopératives dans une Compagnie nationale du charbon surdimensionnée - la plus grande d'Europe - mais toujours incapable de résoudre les problèmes de sa dette, estimée à un milliard d'euros, et de l'absence de rentabilité de la production (Tkocz 2006, Tkocz et Heder 2012, Franik 2010, Paszcza 2010). Cet échec des gouvernements de la mandature 2010-2015 pèse lourdement dans la campagne électorale de 2015. En 2016, la Compagnie Nationale du Charbon est transformée en Groupe Minier Polonais (Polska Grupa Górnicza), qui absorbe en mars 2017 un autre acteur important du secteur, Katowicki Holding WĘglowy et poursuit le difficile chemin des restructurations.

Dans les années 1990, les entreprises sidérurgiques sont transformées en sociétés par action de l'État. Elles commencent leur modernisation sur fonds propres mais les ressources sont insuffisantes et la production, trop chère, est concurrencée par celle des nouveaux pays producteurs. Entre 1991 et 1997, l'importation de produits sidérurgiques est multipliée par sept (Tkocz, 2001). Dans les années 2000, les faillites se succèdent. Des investisseurs étrangers entrent dans le jeu, tel Mittal Steel qui se déploie à partir de 2002. Le groupe Arcelor Mittal Poland détient six sites en Silésie dont la Fonderie Sendzimira/Lénine à Nowa Huta et la Fonderie Katowice. Arcelor Mittal Warszawa reprend la fonderie Huta Warszawa en banlieue nord de la ville (Tkocz, 2015). L'avenir de ces investissements n'est pas assuré en raison de leur financement par la dette, de la baisse du prix des matières premières et des modernisations exigées par les normes environnementales de l'Union européenne.

Sous le Pacte de Varsovie, l'industrie de l'armement était partagée entre États membres dans un système d'interdépendance complexe. En Pologne, le secteur représentait, en 1988, 12\% des exportations. Après une décennie difficile - la commande chute de 50\% après la dissolution du Pacte - l'adhésion de la Pologne à l'OTAN en 1999 semble ouvrir de nouveaux débouchés. Le secteur se consolide autour de deux sociétés à capitaux publics, Bumar (chars, roquettes, munitions) et PZL Mielec (aviation) ${ }^{12}$ pour adapter une production peu concurrentielle sur le marché international. PZL Mielec est rachetée en 2007 par le constructeur américain Sikorsky Aircraft Corporation et assemble des hélicoptères de combat (Jaworski, 2006. Baranowska-Prokop, 2013). Des niches se développent peu à peu (drônes), mais l'ensemble du secteur peine à décoller. 


\section{Les redéploiements de la production de biens de consommation} En 1980, avec la naissance de Solidarność dans les grèves de Gdańsk, les chantiers navals devinrent emblématiques pour la nation entière. Dans les années 1990, le secteur affronte la concurrence de l'Asie du Sud-Est, notamment des naviresconteneurs produits par la Corée du Sud, qui entraîne de nombreuses faillites (Musielak 2001). Les chantiers navals qui survivent se reportent sur des segments de niche, yachts, navires-transporteurs de produits chimiques et de gaz, très gros porteurs polyvalents (Wieloński et Bazydło, 2002). Depuis les années 2000, les trajectoires sont variées. Certaines entreprises continuent de s'étioler. A la chute du régime, les chantiers historiques de Gdańsk emploient 18000 salariés. Les difficultés économiques entraînent une première liquidation et un regroupement avec les chantiers de Gdynia qui fait long feu (1998-2006). Vendus en 2007 à un investisseur ukrainien, les chantiers de Gdańsk affrontent une nouvelle crise lorsqu'ils doivent restituer les aides publiques de l'État jugées contraires au droit de la concurrence par la Commission européenne. L'entreprise réalise ses actifs en cédant du foncier, attractif par sa localisation privilégiée malgré le coût des conversions d'usages. La construction navale s'éteint et, fin 2016, les chantiers de Gdańsk n'emploient plus que 200 salariés. D'autres cessions sont couronnées de succès. Toujours à Gdańsk, dans les chantiers voisins de maintenance de navires, la Holding Remontowa est constituée en 2001 par le rachat de l'entreprise par ses salariés. Elle affiche désormais des bénéfices conséquents. Globalement, le secteur fut fortement mis à mal dans les années 2000 et atteignit son plus bas niveau en 2009, où il employait 23000 salariés. Depuis, il remonte et emploie 32000 salariés en 2016 (données GUS). Forte de son savoir-faire, la construction navale développe des produits de haut de gamme et/ou très spécialisés.

Avant 1989, les industries agro-alimentaires (IAA) s'en tenaient souvent à la première transformation des produits, générant peu de valeur ajoutée. Le secteur comporte des segments très concentrés (alcool, tabac, transformation de fruits et légumes, production d'huile) et des segments qui le sont beaucoup moins. L'entrée dans l'Union européenne a attiré des investissements étrangers qui ont renforcé la concentration des IAA (Kraciuk 2008, Kociszewski et Szwacka-Mokrzycka, 2011). Les brasseries illustrent cette évolution. Dès les premières privatisations, les firmes multinationales ont investi le secteur. La brasserie historique de Żywiec est rachetée en 1994 par le groupe néerlandais Heineken, qui conserve la marque, développe le marketing, contrôle la qualité, et inonde le marché polonais. L'augmentation de la consommation intérieure de bière, qui se substitue progressivement à la consommation de vodka, soutient la demande. La recherche de nouveaux débouchés se fait dans les pays d'émigration, USA, Canada, Irlande. Le concurrent anglais, SABMiller, reprend les marques Tyskie, Lech et Dojlidy et couvre $36 \%$ du marché national. En décembre 2016, il est racheté par le groupe japonais Ahashi. En marge de ces grandes manœuvres, l'agro-alimentaire voit également se développer une base de PME locales qui se positionnent sur le créneau des produits de terroir, bières artisanales, fromages, produits de traiteur (Sadowski, 2002 ; Gołaś et Ścibek 2010).

Une industrie automobile existait dans la République Populaire de Pologne, qui produisait pour son marché intérieur. Cette base est dynamisée par l'ouverture européenne qui entraîne un redéploiement du secteur, en Pologne comme dans 
d'autres pays d'Europe centrale et orientale (Bourdin S, Thiec A, Elissalde B, 2009). $\mathrm{FSM}^{13}$ produisait des voitures sous licence Fiat dans deux usines réputées pour leur qualité, à Tychy et à Bielsko-Biała. En 1992, Fiat profite du premier train de privatisations pour les racheter et spécialiser leurs rôles. Tychy conserve la fabrication de véhicules légers (Fiat 500, Fiat Panda) tandis que Bielsko-Biała produit des composants automobiles. En 1993, Volkswagen reprend l'usine de véhicules agricoles Tarpan à Poznań et la convertit à la production de la Volkswagen Caddy. En 1996, Opel ouvre un nouveau site dans la zone économique spéciale de Gliwice, autour duquel s'implantent rapidement industries intermédiaires et équipementiers automobiles (Domański, 2015). L'entrée de la Pologne dans l'Union européenne entraîne l'apparition de nouveaux producteurs actifs à l'export, Solaris à Poznań, Solbus à Solec Kujawski, ANZ à Kutno. Inversement, des multinationales ouvrent des centres de production en Pologne, Volvo à Wrocław, MAN à Poznań, Scania à Słupsk (Połom, 2015). Si le secteur se porte bien, la pérennité des IDE n'est pas assurée. En 1995, à Varsovie, Daewoo rachète $\mathrm{FSO}^{14}$ pour y produire ses véhicules. Suite aux accords de libre-échange qui dispensent les véhicules coréens des droits de douane, la production est arrêtée en 2011. Le site, partiellement réaménagé, emploie 300 salariés. La dépollution étant trop onéreuse, les installations sont entretenues. Le coût de fonctionnement est couvert par un reliquat d'activités de production (composants automobiles et jeux de Lego) et par la location de bureaux.

La structure sectorielle a profondément changé. Les industries traditionnelles perdent leur poids en emplois et en valeur produite, tandis que les industries de biens de consommation gagnent du terrain, tout en demeurant moyennement qualifiées. Les industries de haute technologie progressent lentement. Faute d'investissements productifs, mais aussi en recherche et développement, elles peinent à résorber les retards technologiques hérités de l'époque socialiste (Dyduch, 2005, Rachwał, 2011b). Les industries de forte valeur qui apparaissent, notamment pharmacie et instruments médicaux, sont peu nombreuses (Świdurska, 2009).

\section{Transformations dans l'espace et politiques d'aménagement}

Désindustrialisation et réindustrialisation n'ont pas affecté de la même manière les territoires. Les disparités régionales héritées de l'histoire (Fig.1) sont confirmées, voire accentuées par ces mutations. Les métropoles attirent de nouvelles industries. Les anciens bassins industriels parviennent à convertir leurs activités contrairement à la façade Est, en franche déprise industrielle.

\section{A. Les aires métropolitaines se convertissent aux industries qualifiées}

Les métropoles sont les grandes gagnantes de la transformation. Si elles ont perdu une partie de leurs industries traditionnelles, ces pertes ont été compensées par les conversions et créations d'activité. Elles furent les premières à attirer les IDE et le mouvement ne se dément pas (Domański, 2002 et 2015). Les activités les plus exportatrices s'y localisent (Komornicki 2006). Les industries spécialisées à forte valeur ajoutée et les industries innovantes s'y développent. Les aires métropolitaines de 
Varsovie et de Poznań sont les plus dynamiques, mais l'ensemble des grandes villes polonaises est concerné (SmĘtkowski, 2008). La répartition sur le territoire de l'industrie pharmaceutique illustre cette sélectivité spatiale. Parmi les dix plus grosses firmes du secteur, toutes ont au moins un établissement à Varsovie. Les aires métropolitaines de Poznań, Łódź et Gdańsk suivent (PWC, 2011).

La métropolisation a réduit le chômage de ces villes à un niveau quasi frictionnel et en fait le moteur du développement de leur région. En janvier 2017, Poznań (2\%) et sa voïvodie la Grande-Pologne (5,9\%) arrivent en tête du classement. Varsovie $(2,8 \%)$ imprime son dynamisme à la Mazovie $(7,4 \%)$, Cracovie $(3,6 \%)$ entraîne la PetitePologne (6,9\%), et la Tricité ${ }^{15}(3,7 \%)$ soutient la Poméranie (7,5\%). Les capitales silésiennes, Katowice (2,9\%) et Wrocław (2,8\%), ne sont pas en reste ${ }^{16}$.

31 Au sein des aires métropolitaines, l'industrie quitte le cœur des agglomérations pour la périphérie. Comme dans d'autres pays post-socialistes, cette mutation est favorisée par une politique de zones franches (Bost, 2010). En 1994, la loi définit des zones économiques spéciales (SSE) ${ }^{17}$ pour le développement des zones en retard de développement ou en conversion industrielle. Quatorze SSE multi-sites voient le jour, donnant naissance à une myriade de zones d'activités dispersées sur l'ensemble du territoire (Coudroy de Lille, 2007). Elles s'étendent rapidement. Au total, les SSE polonaises représentent 6500 ha en 2004, 16200 ha en 2013, 20000 ha en 2015 (Colliers international, 2016). Le dispositif est aménagé à plusieurs reprises. En 2004, pour être en conformité avec le droit européen, les allègements fiscaux sont limités et un plafond national de surface de 14000 hectares est institué. Il passe à 20000 hectares en 2008, puis à 25000 hectares en 2015. Le respect de ce plafond donne lieu un jeu d'écritures : au fil de l'eau, les périmètres non consommés sont déclassés au profit de nouvelles créations. La plus récente refonte confère aux SSE une fonction de soutien à l'innovation, ce qui permet de prolonger leur existence jusqu'en $2026^{18}$.

Contesté pour "n'avoir pas tant été l'instrument d'une politique de long terme, interrégionale et industrielle de l'État qu'un appui offert à des accords locaux particularistes" (SmĘtkowski, 2008:215), le dispositif a bénéficié aux petites villes des périphéries des aires métropolitaines (Domański, 2002 et 2015). Le cas d'école est Niepołomice. Avec 20000 habitants et un château historique, c'est au début des années 1990 une localité périurbaine oubliée, au sud-est de Nowa Huta. En 1994, son maire négocie directement avec Coca-Cola et convainc la multinationale de s'implanter. Par une stratégie de développement constante et conquérante, la municipalité attire 58 entreprises aux activités diverses, totalisant 4600 emplois $^{19}$, et entend poursuivre ce développement. Elle s'est dotée de documents d'urbanisme allouant 540 hectares (dont seulement 215 appartiennent à la SSE) aux activités et investit dans l'amélioration du cadre de vie. Dans l'aire des grandes métropoles, des petites villes déploient des stratégies similaires. 
Fig. 4. Les sites de la zone franche de Łódź (élaboré par A. Geppert et I. Pielesiak, 2017)

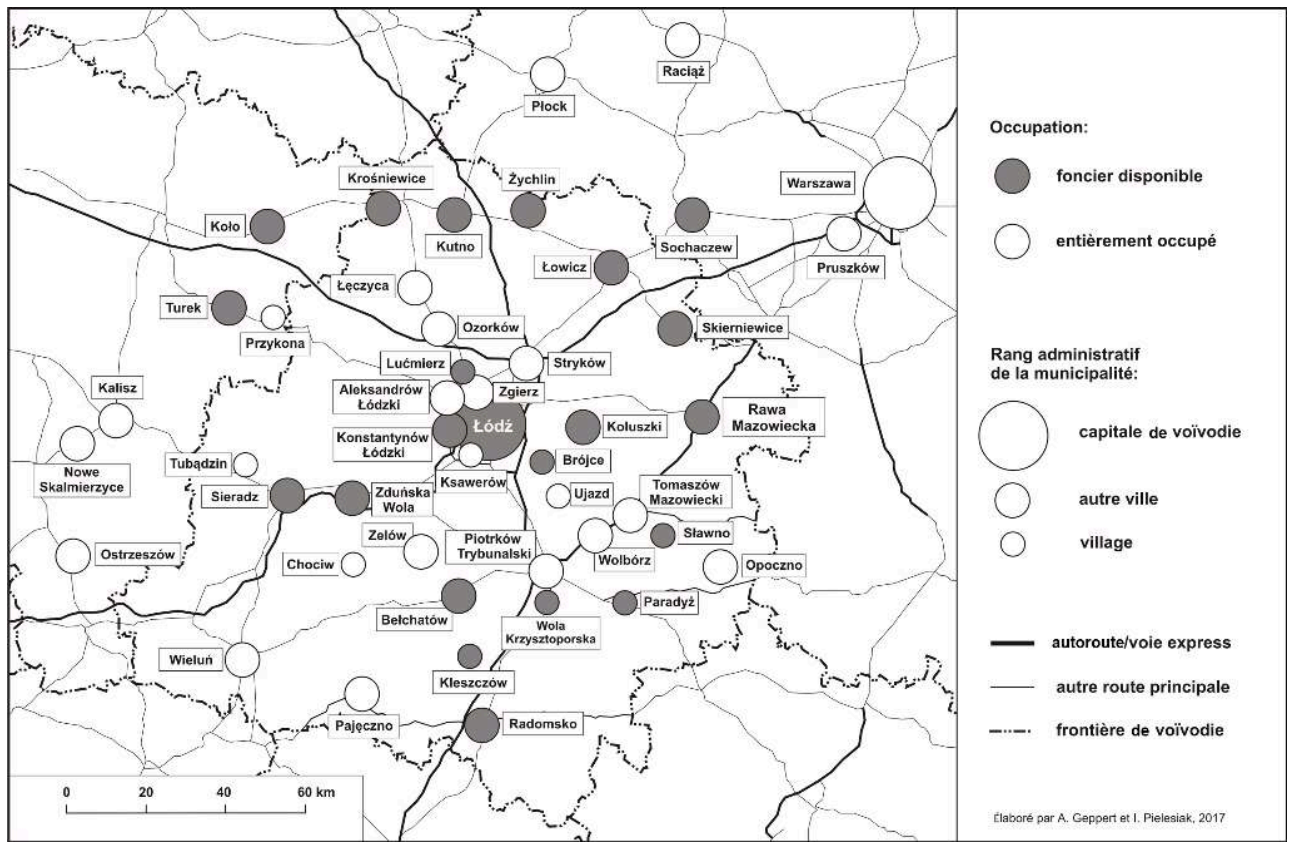

33 A Łódź, la SSE dépasse les limites de la voïvodie (Fig. 4). Aux portes de la ville, elle a permis le développement de nombreuses zones d'activité, où s'implantent des usines nouvelles, souvent délocalisées d'Europe occidentale (Fig. 5).

Fig. 5. Nouvelles usines en " greenfield " : Gilette, Dell et Indesit (gr. Whirlpool). Photos : A. Geppert et I. Pielesiak, 2017

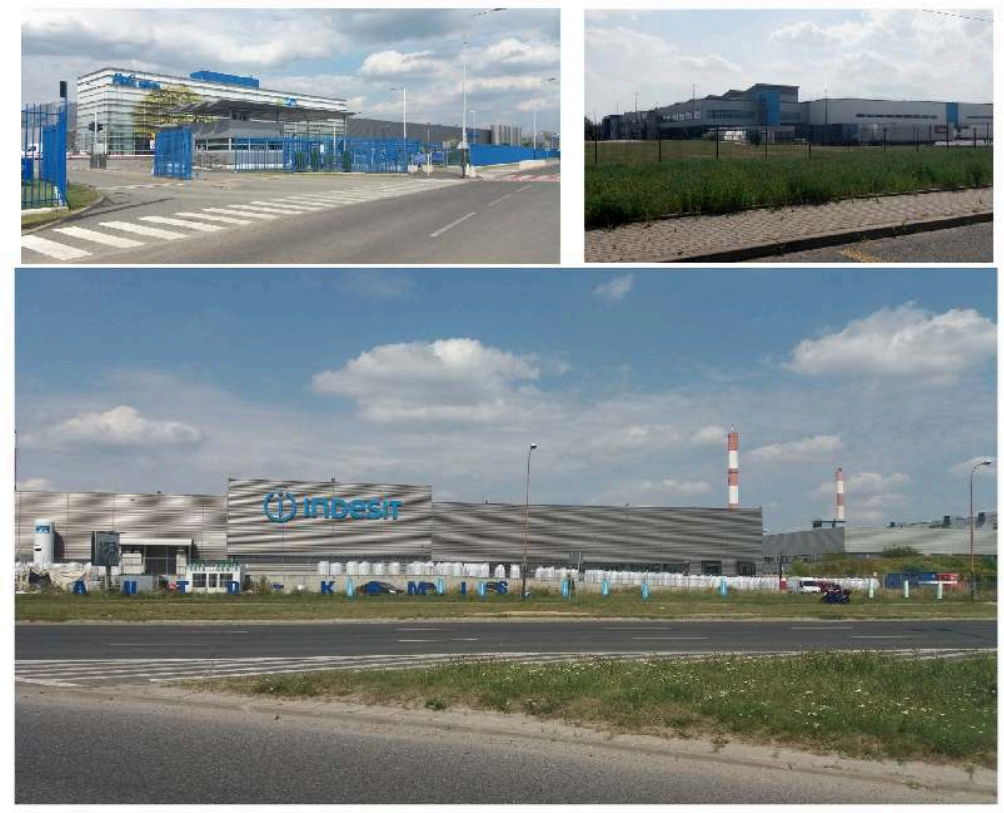


Fig. 6. Réhabilitations phares dans le centre ville de Łódź (élaboré par A. Geppert et I. Pielesiak, 2017)

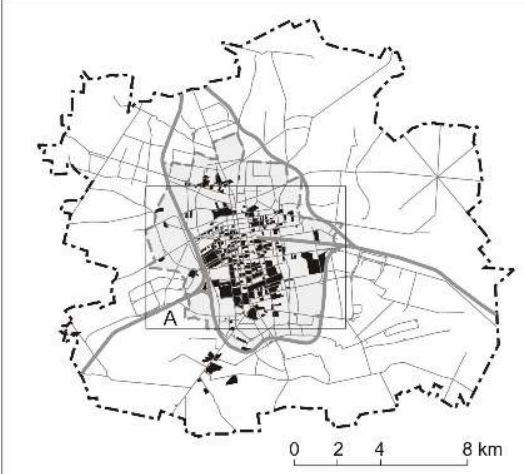

- Terrains industriels

ᄃ] Limite de Łódź en 1915

--- Limite de Łódź depuis 1988

- Chemin de fer

- Voirie

- - Rue Piotrkowska

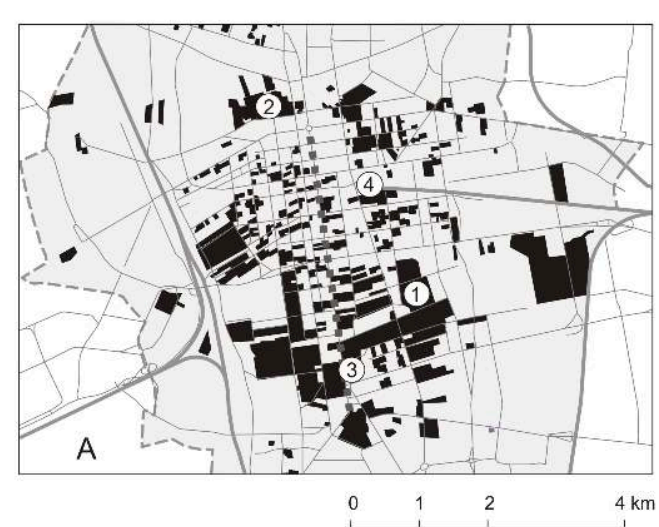

(1) L'usine de Karol Scheibler

(2) L'usine de Izrael Poznańsk

(3) L'usine de Ludwik Geyer

(4) Nouveau Centre de Łódź (NCŁ)

En cœur d'agglomération, l'industrie textile s'éteint et les friches se multiplient. Les rénovations, assez spectaculaires, demeurent rares vu l'abondance des emprises industrielles (Fig. 6). Le musée de la production textile, implanté dans l'ancienne usine Geyer (3) dès les années 1950, est rénové. En 1991, Poznański/Poltex (2) ferme. En 1999, le groupe français Apsys réhabilite l'usine pour en faire un centre commercial qui connaît un franc succès (Manufaktura, Fig. 7), tandis que les logements ouvriers aux alentours pourraient encore servir de décor à un film historique. En 2003, Scheibler/ Uniontex cesse son activité. En 2005-2006, le groupe Opal Property Developments acquiert la friche pour y créer des lofts (Księży Młyn, 1) qui peinent à trouver preneur (Cudny, 2008). Depuis 2007, la municipalité porte un ambitieux projet de nouveau centre-ville ( $\mathrm{NCE}$, (4) ${ }^{20}$ qu'elle réalise par étapes. Redéfini à plusieurs reprises, il entend revitaliser le centre en misant sur la culture (Coudroy de Lille, 2014). Ses opérationsphares sont en cours d'achèvement. L'ancienne centrale électrique EC1 est réhabilitée et convertie en grand équipement culturel. La gare de Łódź Fabryczna, reconstruite et transformée en plate-forme multimodale, a ouvert ses portes en décembre 2016. Candidate pour accueillir l'Expo 2022, Łódź place la réhabilitation urbaine au cœur de son projet («city re:invented»). Entre 2011 et 2016, la municipalité a mené un programme de réhabilitation intégrale de ses bâtiments historiques dégradés, qui a nécessité le relogement temporaire des habitants, mia100 kamienic. A partir de 2017, la réhabilitation s'intensifie pour les logements. Pour l'industrie, les implantations s'effectuent néanmoins en greenfield, aux portes du centre-ville ou bien en périphérie. 
Fig. 7. Manufaktura photo : I. Pielesiak 2013

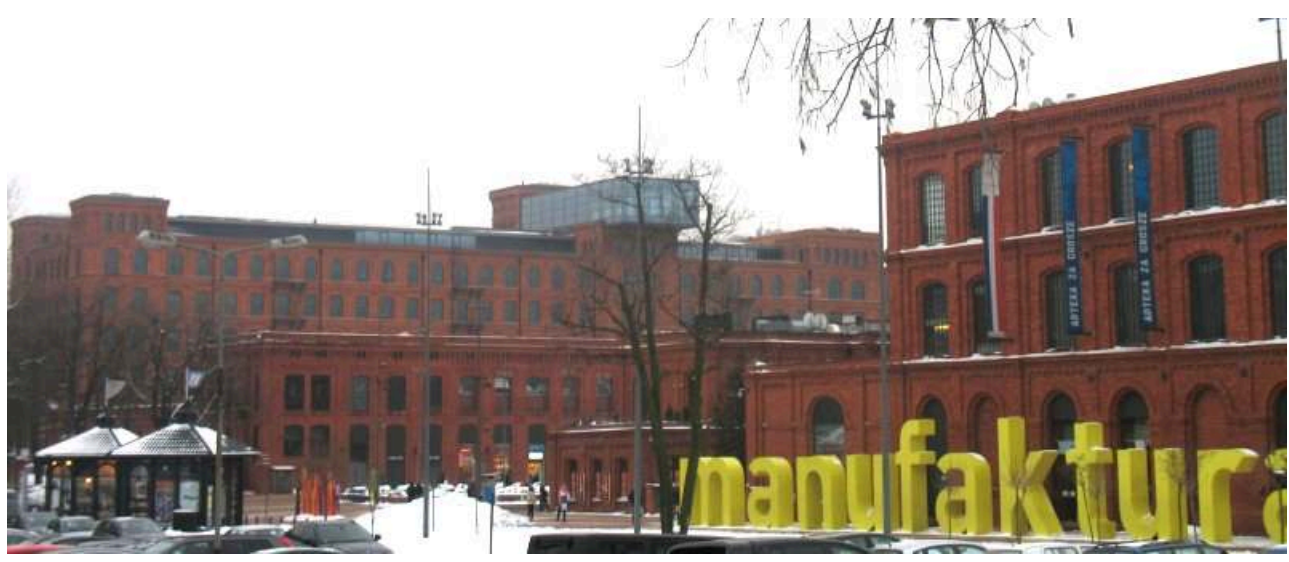

La conversion à "l'économie de la connaissance" se concrétise dans des projets de parcs technologiques, sur le modèle du cluster. En 1996, Cracovie ouvre un Parc Technologique bénéficiant du statut SSE. Les sites qui se développent accueillent plutôt des services que de la haute technologie. A Pychowice le site se situe au contact de l'ambitieux nouveau campus de l'Université Jagellone. Malgré la réalisation du campus et le prolongement de la ligne de tramway permettant d'atteindre rapidement le centre-ville, les investisseurs ne se présentent pas.

\section{B. Le renouveau des anciens bassins industriels contraste avec le déclin des régions rurales}

Dans les bassins industriels, la désindustrialisation est compensée par le développement d'une industrie de biens de consommation moyennement qualifiée dont le fer de lance est le secteur automobile porté, comme Maria Tkocz (2005) a montré sur l'exemple de la Haute-Silésie, par les investissements internationaux. Première concentration industrielle du pays, la Silésie ${ }^{21}$ est confrontée à la restructuration de ses industries. La région présente néanmoins des avantages comparatifs importants. Elle est au cœur de bassins de main d'œuvre et de consommation conséquents, son accessibilité ferroviaire et routière est sans comparaison avec le reste du pays. Avec 7565 hectares, les quatre SSE silésiennes représentent $40 \%$ du foncier des zones franches polonaises. De leur création à 2015, elles auraient permis de créer 102288 emplois et d'en maintenir $23625 . .^{22}$ Les effets sur l'emploi régional sont visibles, avec des taux de chômage nettement inférieurs à la moyenne nationale $(8,6 \%)$ tant en Silésie $(6,8 \%)$ qu'en Basse-Silésie $(7,6 \%)^{23}$. Le bassin industriel de Haute-Silésie (GOP) se déconcentre et s'étend vers le nord et vers l'ouest (Rachwał, 2010). Cependant, la quasi-totalité des implantations sont de type greenfield. Conquérant de nouveaux espaces aux portes des agglomérations moyennes ou grandes, de préférence aux abords de l'autoroute A4 qui traverse le territoire d'est en ouest, cette réindustrialisation ne traite pas les larges friches dues aux activités qui périclitent ou disparaissent, un enjeu majeur pour l'avenir du territoire.

Dans la façade Est, parfois surnommée "Pologne B », la désindustrialisation n'est pas compensée par des activités nouvelles. Les cinq voïvodies qui la composent affichent des taux de chômage entre 10,7 et $14,8 \%^{24}$, très supérieurs à la moyenne nationale de $8,6 \%$. Localement, certains districts ${ }^{25}$ dépassent $20 \%$. Les revenus sont nettement plus 
faibles que dans les autres régions. La façade Est alimente fortement l'émigration pour l'emploi, temporaire ou provisoire. Les industries n'y trouvent ni la main d'œuvre, ni les infrastructures de transport correspondant à leurs attentes. Paradoxalement, les indicateurs non monétaires de qualité de vie sont bons. Les Basses-Carpates détiennent le record de longévité, le système éducatif est performant. Bénéficiaires privilégiées des fonds structurels de la politique de cohésion, certaines villes ont mené des programmes de revitalisation ambitieux. La façade Est pourrait avoir, à l'avenir, une carte à jouer. Quelques villes ont su percer comme Mielec, qui a valorisé la présence du constructeur historique PZL Mielec et la proximité de l'autoroute A4 pour attirer des entreprises du secteur aéronautique dans sa SSE.

\section{L'enjeu industriel dans la politique d'aménagement du territoire}

La stratégie d'aménagement de l'espace national identifie ces différenciations régionales et l'enjeu de la mutation vers une industrie plus qualifiée et plus productive (KPZK, 2011). Elle préconise le renforcement des fonctions métropolitaines des 16 plus grandes villes, moteur de la transition vers une économie de la connaissance. Les villes intermédiaires, nombreuses dans le réseau urbain polonais, doivent diversifier leur portefeuille d'activités. L'accueil des investissements productifs est un objectif majeur, pour lequel il convient de créer les meilleures conditions, notamment par le développement des infrastructures de transport et la mise en avant de spécialisations industrielles plus lisibles et mieux adossées à la recherche-développement. Pour la mise en œuvre de cette politique d'aménagement, l'appartenance à l'Union européenne représente à la fois une opportunité et une contrainte. D'un côté, dans la période 2014-2020, la Pologne dispose de fonds structurels abondants pour soutenir le rattrapage de l'équipement du territoire (infrastructures de transport, réhabilitations) et l'adaptation à la société de la connaissance (industries innovantes, recherche et développement). Inversement, le droit communautaire limite les aides économiques directes (droit de la concurrence) et impose des normes environnementales qui exigent des investissements coûteux, notamment pour les industries lourdes confrontées à un fort endettement.

La désindustrialisation laisse au cœur des agglomérations des friches urbaines et industrielles dont l'emprise peut représenter jusqu'à $20 \%$ de l'espace des villes polonaises. Depuis le milieu des années 2000, des opérations de réhabilitation et de revitalisation ont eu lieu, comme celle de Łódź qui a, dans une certaine mesure, servi de laboratoire. Désormais, une loi sur la revitalisation et un Plan national de revitalisation sont en place. La revitalisation est définie comme un processus visant à faire sortir les zones dégradées d'une situation de crise par une action intégrée. L'accent est mis sur la nécessité de coordonner l'intervention physique (bâti, infrastructures, remise en état environnemental) avec les actions économiques et sociales. Les municipalités élaborent un programme pluriannuel de revitalisation qui sert de cadre pour l'ensemble des acteurs concernés (MIR, 2014). Les fonds structurels 2014-2020 de l'Union européenne ouvrant des possibilités de cofinancement généreuses, de nombreux programmes locaux se mettent en place. 


\section{Conclusion}

Au lieu de la désindustrialisation brutale qui menaçait au début des années 1990, l'industrie polonaise a connu vingt-cinq ans de transformation. Le développement d'activités à plus forte valeur ajoutée, soutenu par les IDE, confère au secteur secondaire davantage de robustesse. La crise des années 2008 le confirme, puisque l'industrie polonaise a bien résisté, notamment grâce à la production des produits de base dont la consommation n'a pas diminué (Rachwał, 2011a). Des mouvements similaires ont lieu dans les pays d'Europe centrale, devenue arrière-cour industrielle de l'Union européenne. Dans un article sur le secteur automobile, Bourdin, Thiec et Elissalde (2009:42) montrent que « sur les territoires centre-européens s'enchevêtrent ainsi trois temporalités : celle de la translation des productions des constructeurs de l'Ouest à la faveur des avantages compétitifs issus de l'effondrement de l'ancien système ; celle de la reconversion des bassins de main-d'œuvre hérités des anciens combinats ; et enfin, celle de la diffusion des normes communautaires de consommation. »

41 Dans ce contexte, les politiques publiques peuvent-elles changer la donne? Au niveau national, le soutien direct aux secteurs en difficulté semble avoir au mieux retardé le déclin, à l'instar de ce qu'avait connu l'Europe occidentale avec le charbon et l'acier. Le recours massif aux zones franches demeure ambigu: d'un côté, en augmentant l'attractivité-prix, il catalyse la mutation du système productif. De l'autre, avec la mobilité accrue des firmes internationales à l'affût d'opportunités de court terme, la pérennité des industries implantées est incertaine. Au niveau local, la présence d'une personnalité motrice peut faire la différence, comme l'action du maire à Niepołomice.

Depuis début 2016, une nouvelle politique industrielle est mise en œuvre . Le "plan Morawiecki ${ }^{26}$ repose sur l'idée que le rattrapage de développement qui a tiré la croissance depuis trente ans risque de s'essouffler en raison de cinq «trappes » de développement: des revenus trop moyens qui ne tirent pas la consommation intérieure ; un déséquilibre entre IDE, toujours souhaités, et investissements nationaux, notoirement insuffisants, qu'il convient de stimuler ; une production trop banale, dont il faut tirer vers le haut la qualité et le contenu technologique ; une démographie atone qu'il faut stimuler; une faiblesse institutionnelle à dépasser. Cinq orientations stratégiques doivent y remédier, au premier rang desquelles est placée la réindustrialisation. Un plan d'investissement de mille milliards de PLN (220 milliards d'euros), composé pour presque la moitié par la mobilisation des fonds structurels de l'Union européenne, marque le début d'une ère de " patriotisme économique » et d'une implication forte de l'État dans le développement industriel, conçu non seulement comme politique sectorielle, mais aussi comme politique spatialisée, avec le développement de clusters et de bassins industriels. Nous sommes face à une véritable volonté d'aménagement du territoire; les prochaines années montreront si le succès est au rendez-vous. 


\section{BIBLIOGRAPHIE}

Bureau central de statistique (GUS), 1990-2014. Annuaires de l'industrie (http://stat.gov.pl/).

Baranowska-Prokop E., 2013, Umowy offsetowe a modernizacja polskiego przemysłu obronnego, [Accords d'offset et modernisation de l'industrie d'armement polonaise], Przegląd

Zachodniopomorski, z. 3, t. 2, p. 23-37.

Bartosik K., 2013, Zmiany strukturalne i koniunkturalne a zatrudnienie w polskim przemyśle przetwórczym, [Tranformations structurelles et conjoncturelles et emploi dans les industries de transformation polonaises], Gospodarka Narodowa, 9 (265), p. 91-115.

Bost F., dir, 2010, Atlas mondial des zones franches, Paris, La Documentation Française, 318p.

Bourdin S., Thiec A. L., Elissalde B., 2009, Le changement spatial dans l'industrie automobile en Europe centrale et orientale : entre effets d'héritage, cycles de vie et transition, Géocarrefour, 1 septembre 2009, 84/3, p. 193-204., http://dx.doi.org/10.4000/geocarrefour.7438

Brezdeń P. et Spallek W., 2008, Specjalne strefy ekonomiczne w przestrzeni gospodarczej województwa dolnośląskiego, [Les zones économiques spéciales dans l'espace économique de la région de BasseSilésie], Prace Komisji Geografii Przemysłu PTG, nr 10, p. 217-229

Ciechowski M., 2014, Zmiany struktury przestrzennej przemysłu województwa małopolskiego, [Les changements de structure spatiale de l'industrie de la voïvodie de Petite-Pologne], Prace Komisji Geografii Przemysłu PTG, nr 27, p. 197-210.

Colliers international, 2016, Specjalne Strefy Ekonomiczne w Polsce. [Les zones économiques spéciales en Pologne], 67p.

Coudroy de Lille L., 2007, « Les zones économiques spéciales en Pologne : un tremplin pour l'emploi régional ou des miettes de la mondialisation? ", Annales de géographie, 6/2007(n658), p. 645-666.

Coudroy de Lille L., 2014, "Politique culturelle et revitalisation urbaine à Lódź", in Djament-Tran G., San-Marco P., La métropolisation de la culture et du patrimoine, Editions du Manuscrit, p.107-121

Cudny, W., 2008, Rola prywatnych inwestorów $w$ rewitalizacji terenów poprzemysłowych $w$ Łodzi, [Le rôle des investisseurs privés dans la réhabilitation des terrains post-industriels à Łódź],

ZarzĄdzanie Krajobrazem Kulturowym, Prace Komisji Krajobrazu Kulturowego, nr 10, p. 379-385.

Domański B., 2002, Zagraniczne inwestycje przemysłowe a obszary metropolitalne w Polsce, [L'investissement étranger dans l'industrie et les aires métropolitaines en Pologne], Prace Komisji Geografii Przemysłu PTG, nr 4, p. 9-17

Domański B., 2006, Polski przemysł na tle przemysłu Europy Środkowej i Wschodniej, [L'industrie polonaise dans le contexte de l'industrie d'Europe centrale et orientale],Prace Komisji Geografii Przemysłu PTG, nr 8, p. 27-36.

Domański B., 2015, Współczesne procesy przemian regionalnych przemysłu Polski - próba interpretacji, [Les processus contemporains de transformation régionale de l'industrie polonaise], Prace Komisji Geografii Przemysłu (PTG), nr 29, z. 4, p. 40-53.

Dyduch J., 2005, Zmiany strukturalne w przemyśle w latach 1991-2001, [Les changements structurels dans l'industrie au cours des années 1991-2001], Zeszyty Naukowe/Akademia Ekonomiczna w Krakowie, nr 668, p. 113-126. 
Franik T., 2010, Analiza zmian udziału przemysłu wydobywczego w osiagganych wynikach makroekonomicznych gospodarki w okresie przemian ustrojowych $w$ Polsce, [Analyse de l'évolution de l'apport des industries d'extraction aux résultats de l'économie polonaise à l'époque des changements de régime en Pologne], Komputerowo zintegrowane zarzĄdzanie, Oficyna Wydawnicza Polskiego Towarzystwa ZarzĄdzania Produkcją, Opole, p. 431-439.

Gierańczyk W. et Stańczyk A., 2001, OkrĘgi przemysłowe w Polsce u progu XXI wieku, [Les bassins industriels en Pologne au seuil du XXI siècle], Prace Komisji Geografii Przemysłu PTG, nr 3, p. 61-69.

Gołaś Z. et Ścibek M., 2010, Analiza tendencji zmian na polskim rynku piwa, [Analyse des tendances d'évolution sur le marché polonais de la bière], Journal of Agribusiness and Rural Development, 1(15), p. 67-80.

Jaworski J., 2006, Restrukturyzacja polskiego przemysłu zbrojeniowego, [La restructuration de l'industrie d'armement polonaise], Prace Komisji Geografii Przemysłu PTG, nr 9, p. 130-142.

Kaliński J., 2009, Transformacja gospodarki polskiej w latach 1989-2004, [La transformation de l'économie polonaise dans les années 1989-2004], Oficyna Wydawnicza SGH, Warszawa, 145p.

Kociszewski M. et Szwacka-Mokrzycka J., 2011, Uwarunkowania rozwoju przemysłu spożywczego po przystąpieniu Polski do Unii Europejskiej, [Les conditions de développement de l'industrie agroalimentaire après l'accession de la Pologne à l'Union européenne], Zeszyty Naukowe SGGW w Warszawie - Problemy Rolnictwa Światowego, t. 11 (26), p. 67-77.

Koncepcja Przestrzennego Zagospodarowania Kraju 2030 (KPZK 2030), 2011, [Conception de l'Aménagement du Territoire National 2030], arrêtée par le gouvernement polonais en décembre 2011.

Komornicki T., 2006, Eksport w ujęciu regionalnym jako miernik rozwoju przemysłu, [L'export sur le plan régional comme un gage de développement industriel], Prace Komisji Geografii Przemysłu (PTG), nr 8, p. 167-178.

Lachiewicz S. et Zakrzewska-Bielawska A., 2010, Kierunki zmian w strukturach organizacyjnych przedsiębiorstw przemysłowych, [Les changements dans les structures organisationnelles des entreprises industrielles], Acta Universitatis Lodziensis. Folia Oeconomica 234, p. 23- 43.

Kraciuk J., 2008, Koncentracja produkcji w polskim przemyśle spożywczym, [La concentration de la production dans l'industrie agro-alimentaire polonaise], Problemy Rolnictwa Światowego, Zeszyty Naukowe SGGW w Warszawie, t. 5, z. 20, p. 33-41.

Marczyńska-Witczak E., 2001, Procesy dezindustrializacji przestrzennej w latach dziewięćdziesiĄtych na przykładzie Łodzi, [Les processus de désindustrialisation spatiale dans les années 1990, exemple de Łódź], Prace Komisji Geografii Przemysłu PTG, nr 2, p. 41-48.

Miedziński B., 2015, Polityka przemysłowa dla Polski - wyzwania i zagrożenia, [Une politique industrielle pour la Pologne - défis et menaces]. In Poniatowska-Jaksch M, Sobiecki R (red.), Przedsiębiorstwo przemysłowe w Polsce, Oficyna Wydawnicza SGH, Warszawa, p. 47-74.

Musielak J., 2001, Procesy restrukturyzacji w przemyśle okrĘtowym (na przykładzie Stoczni Szczecińskiej S.A.), [Les processus de restructuration de l'industrie navale, exemple des chantiers de Szczecin], Prace Komisji Geografii Przemysłu PTG, nr 3, p. 155-166.

Paszcza H., 2010, Procesy restrukturyzacyjne w polskim górnictwie wEgla kamiennego w aspekcie zrealizowanych przemian i zmiany bazy zasobowej, [Les processus de restructuration de l'exploitation minière de charbon au regard des transformations réalisées], Górnictwo i Geoinżynieria, r. 34, z. 3, s. 63-82. 
Połom M., 2015, Przestrzenne aspekty produkcji i eksportu autobusów w Polsce w latach 1989-2014, [Aspects spatiaux de la production et de l'export d'autobus en Pologne dans les années 1989-2014], Prace Komisji Geografii Przemysłu PTG, nr 29, z. 1, p. 56-72.

Polska Agencja Inwestycji Zagranicznych, 2014, Agence Polonaise des investissements étrangers, http://www.paiz.gov.pl/pl

Pricewaterhouse Coopers International Limited (PWC), 2011, Wkład innowacyjnego przemysłu farmaceutycznego $w$ rozwój polskiej gospodarki, [L'apport des industries pharmaceutiques innovantes dans le développement de l'économie polonaise], 75p.

Rachwał T., 2006, Efekty restrukturyzacji wybranych przedsiębiorstw przemysłowych Polski PołudniowoWschodniej, [Les effets de la restructuration d'établissements industriels choisis de la Pologne du sud-est], Prace Komisji Geografii Przemysłu PTG, nr 9, p. 98-115

Rachwał T., 2010, Struktura przestrzenna i działowa przemysłu Polski na tle Unii Europejskiej w dwudziestolecie rozpoczĘcia procesów transformacji systemowej, [Structure spatiale et sectorielle de l'industrie polonaise dans le contexte de l'Union européenne vingt ans après le début des processus de transformation du système], Prace Komisji Geografii Przemysłu PTG, 16, p. 105-124.

Rachwał T., 2011a, Wpływ kryzysu na zmiany produkcji przemysłowej w Polsce, [L'impact de la crise sur les évolutions de la production industrielle en Pologne], Prace Komisji Geografii Przemysłu PTG, 17, p. 99-113.

Rachwał T., 2011b, Industrial restructuring in Poland and other European Union states in the era of economic globalization, [La restructuration industrielle en Pologne et dans d'autres états de l'Union Européenne dans l'ère de la globalisation économique], Procedia Social and Behavioral Sciences, 19, p. 1-10.

Rada ministrów, 1993, Polityka przemysłowa. Założenia. Program realizacji w latach 1993-95, [Conseil des ministres, 1993. La politique industrielle. Fondements. Programme 1993-1995].

Sadowski A., 2002, Restrukturyzacja polskiego przemysłu piwowarskiego, [La restructuration de l'industrie brassicole], Instytut Technologii Eksploatacji, Radom.

SmĘtkowski M., 2008, Rola specjalnych stref ekonomicznych w kształtowaniu struktury przestrzennej przemysłu $w$ Polsce, [Le rôle des zones économiques spéciales dans la structuration de l'espace industriel en Pologne], Prace Komisji Geografii Przemysłu PTG, 10, p. 204-216.

Świdurska A., 2009, Kształtowanie się przemysłu wysokiej techniki w Polsce, [Le développement de l'industrie de haute technologie en Pologne], Prace Komisji Geografii Przemysłu PTG, 13, p. 56-67.

Tkocz M., 2001, Restrukturyzacja przemysłu regionu tradycyjnego, [La restructuration de l'industrie d'une région traditionnelle], Katowice, Wydawnictwo Uniwersytetu Śląskiego.

Tkocz M., 2005, La restructuration socio-économique du Bassin Industriel de Haute-Silésie, Géocarrefour, 1 janvier 2005, vol. 80, n¹, p. 49-58., http://dx.doi.org/10.4000/geocarrefour.954

Tkocz M., 2006, Efekty restrukturyzacji górnictwa wĘgla kamiennego w Polsce, [Les effets de la restructuration de l'exploitation minière du charbon en Pologne], Prace Komisji Geografii Przemysłu PTG, nr 9, p. 28-39.

Tkocz M., 2015, Tradycyjny okrĘg przemysłowy z perspektywy 25-lecia funkcjonowania w gospodarce rynkowej w Polsce. Przykład GórnoślĄskiego OkrĘgu Przemysłowego, [Un bassin industriel traditionnel après 25 ans de fonctionnement dans une économie de marché en Pologne, cas du bassin industriel de Haute-Silésie], Prace Komisji Geografii Przemysłu PTG, nr 29, z. 4, s. 112-126. 
Tkocz M. et Heder A., 2012, Działalność innowacyjna upadajĄcej branży przemysłowej na przykładzie górnictwa wĘgla kamiennego, [Les activités innovantes d'un secteur industriel en déclin, cas de l'exploitation minière du charbon], Prace Komisji Geografii Przemysłu PTG, nr 20, p. 134-146.

Wiedermann K., 2004, Wybrane problemy kształtowania siĘ nowej struktury przemysłowej na obszarze GOP, [Aspects choisis de la formation d'une nouvelle structure industrielle dans l'espace du bassin minier de Haute-Silésie], Prace Komisji Geografii Przemysłu PTG, nr 7, p. 53-61.

Wieloński A. et Bazydło A., 2002, Proces integracji z UniĄ EuropejskA a przemiany strukturalne w przemyśle Polski, [L'intégration à l'Union européenne et les transformations structurelles de l'industrie polonaise], Prace Komisji Geografii Przemysłu PTG, 4, p. 19-23.

\section{NOTES}

1. En 2014. A la même date, il représente respectivement $17,6 \%$ en France et $21,9 \%$ dans l'ensemble de l'Union européenne à 28. Données Eurostat.

2. Entre 1995 et 2015 , respectivement $-26,3 \%$ pour l'Union européenne à 28 et $-32,3 \%$ pour la France. Données Eurostat.

3. Entre 1995 et 2015 , respectivement $-17,2 \%$ pour l'Union européenne à 28 et $-26,6 \%$ pour la France. Données Eurostat.

4. $\mathrm{Pl}$ : Główny Urząd Statystyczny

5. Żyrardów doit son nom à un ingénieur et inventeur Français, Philippe de Girard, qui fut directeur de l'usine.

6. Aujourd'hui Lviv, en Ukraine

7. $\mathrm{Pl}$ : okrĘg przemysłowy

8. $\mathrm{Pl}$ : GórnoślĄski OkrĘg Przemysłowy

9. $\mathrm{Pl}$ : Centralny OkrĘg Przemysłowy

10. $\mathrm{Pl}$ : Ziemia obiecana. D’après le roman éponyme publié en 1897-98 par Władysław Reymont (1867-1925), prix Nobel de littérature 1924.

11.

Leszek Balcerowicz (né en 1947). Professeur en économie, deux fois ministre des Finances (19891991 et 1997-2001). Son plan instaure une politique de rigueur.

12. Pl : Polskie Zakłady Lotnicze (Travaux d'Aviation Polonais)

13. Fabryka Samochodów Małolitrażowych (FSM) (Fabrication de Véhicules de petite Cylindrée) associait l'État polonais, majoritaire, à Fiat, minoritaire. Elle produisait la déclinaison polonaise des voitures familiale Fiat $125 \mathrm{P}$ et micro Fiat 126P.

14. Fabryka Samochodów Osobowych (FSO) (Fabrication de Véhicules Individuels) produisait des voitures conçues par les ingénieurs polonais (Polonez, Syrena)

15. Unité urbaine multipolaire structurée par Gdańsk, Sopot et Gdynia

16. Données GUS 2017.

17. $\mathrm{Pl}$ : Specjalne strefy ekonomiczne (SSE)

18. Respectivement: Katowice, 2348 ha ; Wałbrzych, 3502ha. Legnica, 1341 ha. Kamienna Góra, 374ha. Données Colliers 2016.

19. Données 2013, municipalité de Niepołomice.

20. Nowe Centrum Łodzi

21. La partie polonaise de la Silésie, du bassin industriel de la Haute-Silésie à la frontière allemande

22. Données au 31.12.2015 Collier international 2016.

23. Données GUS janvier 2017 
24. Du nord au sud : Varmie-Mazurie $14,8 \%$. Podlachie 10,7 \%. Lublin 10,8 \%. Sainte-Croix $11,1 \%$. Basses-Carpates 11,9\%. Données GUS à la fin du mois de janvier 2017.

25. $\mathrm{Pl}$ : Powiat

26. Uchwała NR 14/2016 z dnia 16 lutego 2016 r. w sprawie przyjĘcia «Planu na rzecz odpowiedwialnego rozwoju », RM-111-18-16.

\section{RÉSUMÉS}

En Pologne, depuis 1989, la part de l'industrie dans la création de richesses a légèrement augmenté malgré les destructions d'emplois. L'entrée dans l'économie de marché et l'accession à l'Union européenne ont déclenché des processus complexes, associant industrialisation et désindustrialisation. L'impact de ces changements varie selon les territoires. Il y a des gagnants, les métropoles et les bassins industriels historiques attractifs aux IDE, et des perdants.

Le présent article analyse ces évolutions en montrant l'importance des structures spatiales héritées de l'histoire. Il interroge l'efficacité de l'action publique visant à soutenir ces transformations, restructurations industrielles et zones franches.

Since 1989, in Poland, the share of industry in the national GDP has slightly increased, in spite of job destructions. In the Polish industrial transformation triggered by the access to market economy and to the European Union, industrialisation and deindustrialization are combined. Territorial impacts of these changes are diverse. There are winners, metropolitan areas and historic industrial regions attractive to FDI, and there are loosers.

The present paper analyzes these changes, showing the importance of spatial structures inherited from history. It questions the efficiency of public policies designed to foster these changes, industrial restructurations and free zones.

Nach 1989 ist der Anteil der Industrie im nationalen BIP in Polen, trotz höherer Arbeitslosenzahl, gestiegen. Die Einführung der freien Marktwirtschaft und der Eintritt in die EU lösten ein kompliziertes Transformationsprozess aus, der gleichzeitig Industrialisierung und Deindustrialisierung umfasst. Daraus resultierende infrastrukturelle Folgen sind uneinheitlich. $\mathrm{Zu}$ den Gebieten, die daraus am meisten profitieren, gehören Großstadtgebiete und Industrieballungsräume, welche sich als besonders attraktiv für Auslandsinvestitionen herausgestellt haben.

Im vorgestellten Artikel liegen für die oben genannten Prozesse Analysen zu Grunde, die die historische Rolle der Infrastrukturen darstellen. Die Analyse wertet die Effektivität von unterstützenden Maßnahmen, der industriellen Umstrukturierung, sowie subventionierten Gewerbegebiete aus. 
INDEX

Mots-clés : Pologne ; industrialisation ; désindustrialisation ; aire métropolitaine ; bassin industriel ; politique industrielle ; zone franche ; aménagement du territoire.

Keywords : Poland ; industrialization ; deindustrialization ; metropolitan area ; industrial region ; industrial policy ; free zone ; spatial planning.

Schlüsselwörter : Polen ; Industrialisierung ; Deindustrialisierung ; Metropolregion ; Industrierevier ; industrielle Politik ; Freihandelszone ; Raumordnung

\section{AUTEURS}

\section{ANNA GEPPERT}

Professeur des Universités, Paris-Sorbonne, Président d'AESOP (Association of European Scools of

Planning), anna.geppert@paris-sorbonne.fr

IWONA PIELESIAK

Docteure, Université de Łódź, Faculté de Géographie, i.pielesiak@interia.pl 